\title{
MECANISMOS DE CONTROL PARA EL MANEJO DE LOS ANTICIPOS EN PROCESOS DE CONTRATACIÓN DEL \\ ESTADO
}

Carlos Felipe Córdoba Larrarte María Camila Parra Valbuena

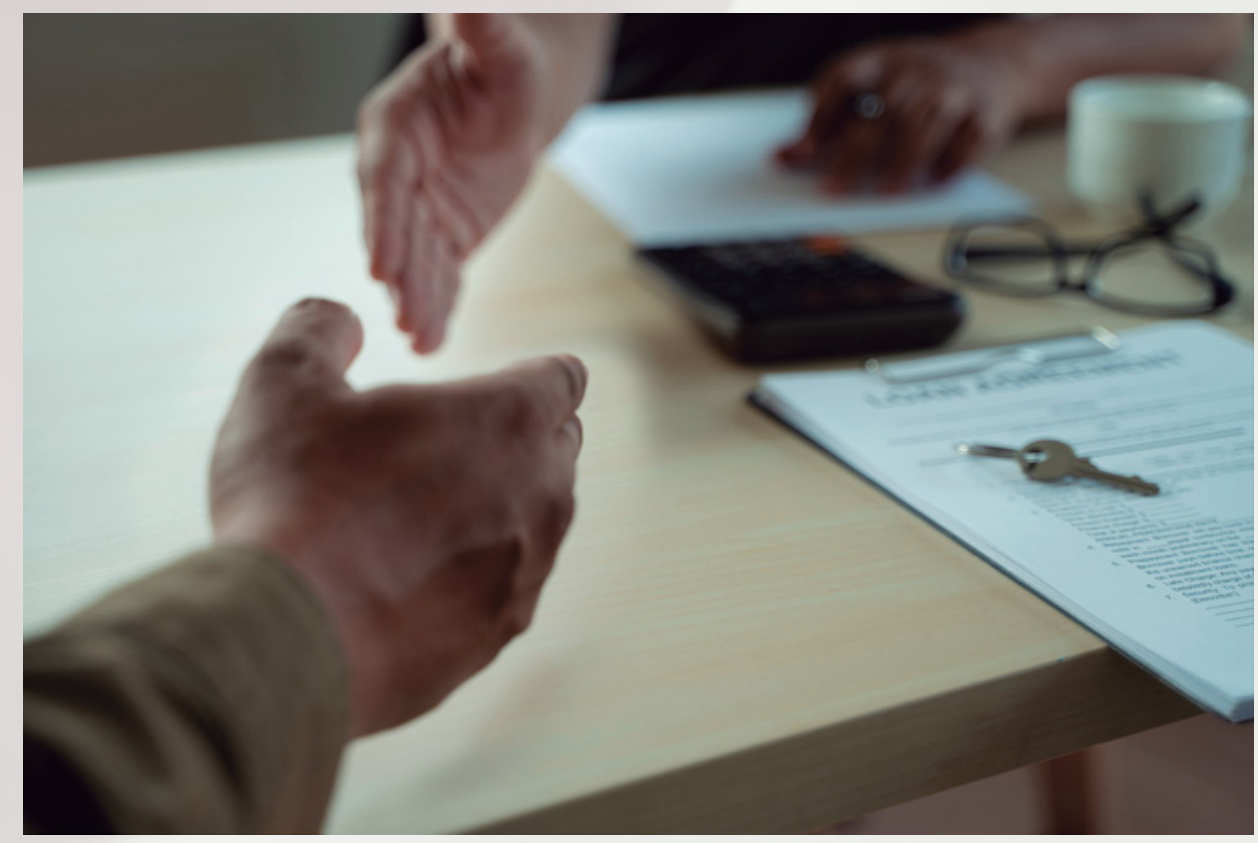





\title{
MECANISMOS DE CONTROL PARA EL MANEJO DE LOS ANTICIPOS EN PROCESOS DE CONTRATACIÓN DEL ESTADO
}

\author{
Carlos Felipe Córdoba larrarte \\ María Camila Parra Valbuena \\ Institución Universitaria Politécnico Grancolombiano
}

\section{Resumen}

Desde una perspectiva normativa, doctrinal y jurisprudencial, el presente artículo de revisión bibliográfica, desarrollado con el método cualitativo, aborda el concepto del anticipo en los procesos de contratación estatal como una figura consagrada en la ley, que permite a los contratistas iniciar la ejecución de las responsabilidades adquiridas en la relación contractual. El anticipo es un adelanto o avance del valor del contrato que se otorga a los contratistas con el objeto de cubrir costos asociados a las obligaciones que los vinculan en el contrato. Para revisar el tema propuesto, se analizarán los mecanismos de control existentes para el manejo de los anticipos y se ahondará en su idoneidad para advertir un eventual escenario de corrupción producto del mal manejo de los recursos públicos. Por último, se examinarán algunos procesos adelantados por la Contraloría General de la República, a la luz de varios fallos de responsabilidad fiscal, los cuales permitirán concluir acerca de la aplicación efectiva de la figura del anticipo por parte de los contratistas del Estado colombiano.

Palabras clave: anticipo, contratación estatal, responsabilidad, normatividad, corrupción, incumplimiento.

Los autores: Carlos Felipe Córdoba Larrarte, estudiante de Derecho. ORCID: 0000-0001-8931-9453. Correo electrónico: cacordoba7@poligran.edu.co

María Camila Parra Valbuena, estudiante de Derecho. ORCID: 0000-0002-0115-2618. Correo electrónico: maparrav6@poligran.edu.co

Recibido: 6 de septiembre de 2021; evaluado: 6 de octubre de 2021; aceptado: 18 de octubre de 2021. 


\title{
CONTROL MECHANISMS FOR THE MANAGEMENT OF ADVANCES IN STATE PROCUREMENT PROCESSES
}

\author{
Carlos Felipe Córdoba larrarte \\ María Camila Parra Valbuena \\ Institución Universitaria Politécnico Grancolombiano
}

\begin{abstract}
From a normative, doctrinal, and jurisprudential perspective, and developed with the qualitative method, this review article examines advances in state procurement processes as a legal feature, which allows contractors to start executing the responsibilities acquired in the contractual relationship. An advance is an early payment of the value of the contract, granted to contractors to cover costs associated with the obligations binding them in the contract. To address the proposed issues, the existing control mechanisms for managing advances are analyzed, as well as their conception from the normative and jurisprudential perspectives, their suitability for detecting a possible scenario of corruption resulting from the mismanagement of public resources, and whether they offer legal certainty for contracting entities. Finally, some investigations processed by the Office of the Comptroller General of the Republic are examined, considering several decisions of fiscal responsibility resulting from fiscal findings issued by the entity, which allow drawing conclusions on the effective application of the advance payment figure by contractors of the Colombian state.
\end{abstract}

Keywords: advance payment, state procurement, responsibility, regulations, corruption, non-compliance.

The authors: Carlos Felipe Córdoba Larrarte, law student. ORCID: 0000-0001-8931-9453. E-mail: cacordoba7@poligran.edu.co

María Camila Parra Valbuena, law student. ORCID: 0000-0002-0115-2618. E-mail: maparrav6@ poligran.edu.co

Received: September 6, 2021; evaluated: October 6, 2021; accepted: October 18, 2021. 


\title{
MECANISMOS DE CONTROLE PARA A GESTÃO DE ADIANTAMENTO EM PROCESSOS DE CONTRATAÇÃO PELO ESTADO
}

\author{
Carlos Felipe Córdoba larrarte \\ María Camila Parra Valbuena \\ Institución Universitaria Politécnico Grancolombiano
}

\section{Resumo}

De uma perspectiva normativa, doutrinal e jurisprudencial, este artigo de revisão bibliográfica, desenvolvido com o método qualitativo, aborda o conceito de adiantamento nos processos de contratação pública como uma figura consagrada na lei, que permite aos contratistas iniciar a execução das responsabilidades adquiridas na relação contratual. O adiantamento é um sinal do valor do contrato que é outorgado aos contratistas a fim de cobrir os gastos associados com as obrigações que os vinculam no contrato. Para revisar esse tema, são analisados os mecanismos de controle existentes para a gestão dos adiantamentos e se aprofunda em sua idoneidade para advertir um eventual cenário de corrupção produto da má gestão dos recursos públicos. Por último, são examinados alguns processos realizados pela Controladoria-Geral da República, à luz de várias decisões de responsabilidade fiscal, as quais permitem concluir sobre a aplicação efetiva da figura do adiantamento por parte dos contratistas do Estado colombiano.

Palavras-chave: adiantamento, contratação estatal, responsabilidade, normatividade, corrupção, descumprimento.

Os autores: Carlos Felipe Córdoba Larrarte, estudante de Direito. ORCID: 0000-0001-8931-9453. Correio eletrônico: cacordoba7@poligran.edu.co

María Camila Parra Valbuena, estudante de Direito. ORCID: 0000-0002-0115-2618. Correio eletrônico: maparrav6@poligran.edu.co

Recebido: 6 de setembro de 2021; avaliado: 6 de outubro de 2021; aceito: 18 de outubro de 2021. 


\section{Introducción}

El anticipo contractual es una figura en virtud de la cual la entidad contratante entrega un dinero al contratista como forma de financiar el inicio de la ejecución del objeto contratado. La Agencia Nacional para la Contratación Pública, Colombia Compra Eficiente, ha conceptuado que el anticipo es:

[...] un adelanto o avance del precio que no ha sido causado, el cual se entrega para la iniciación del objeto contractual, la atención de los gastos preliminares y su aplicación debe realizarse de manera exclusiva a la ejecución del contrato, razón por la cual tales recursos son públicos y deben ser debidamente amortizados. ${ }^{1}$

Los recursos que se giran por tal concepto no se integran al patrimonio del contratista y, por ello, en palabras de Matallana, ${ }^{2}$ es necesario amortizar el respectivo valor en los pagos periódicos que se pactan en el contrato, razón por la cual la jurisprudencia ha considerado que dicha figura es propia de los contratos de tracto sucesivo, concepto que también ha expresado la Contraloría, tiempo atrás. ${ }^{3}$

Por la mencionada finalidad y la necesidad de amortización, el anticipo se distingue del pago anticipado en el que el desembolso de los recursos sí constituye un pago efectivo del precio pactado y, por lo tanto, sí se integran al patrimonio del contratista. El anticipo, entendido de ese modo, no es una retribución por la ejecución del contrato, por lo anterior, según Pérez, ${ }^{4}$ el dinero que se entrega a su título continúa perteneciendo a la entidad estatal y, por lo mismo, conserva su carácter de patrimonio del Estado, hasta tanto se amortice en los pagos sucesivos pactados en cada caso. ${ }^{5}$

Los dineros que integran el anticipo, entonces, son bienes de la entidad pública contratante administrados por el contratista, por lo que la doctrina ha reconocido

1 Colombia Compra Eficiente, "Concepto 3185 del 21 de febrero de 2018", https://crconsultorescolombia. com/concepto-no-3105-anticipo-pago-anticipado.php (acceso septiembre 25, 2021).

2 Ernesto Matallana Camacho, Manual de contratación de la Administración pública: reforma de la Ley 80 de 1993 (Bogotá: Universidad Externado de Colombia, 2009), 854 y ss.

3 República de Colombia, Contraloría General de la República, "Concepto Jurídico No. 7461. Febrero 07 de 2006", https://www.yumpu.com/es/document/read/51399181/el-anticipo-en-contratos-estatales-el-anticipoes-la-suma- (acceso agosto 25, 2021).

4 Carlos Eduardo Pérez Rueda, "El amparo de anticipo en el seguro de cumplimiento entre particulares", RIS 37, núm. 21 (2012): 53, https://revistas.javeriana.edu.co/index.php/iberoseguros/article/view/11469/10001 (acceso agosto 25, 2021).

5 República de Colombia, Consejo de Estado, Sala de lo Contencioso Administrativo, Sección Tercera, Sentencia del 13 de septiembre de 1999, Radicado 10 607, M. P. Ricardo Hoyos Duque; Sentencia del 8 de agosto de 2001, Expedientes acumulados AC10966 y AC11275, M. P. María Elena Giraldo Gómez. 
que dicha entidad, titular del recurso, tiene derecho a recibir los rendimientos financieros que este produzca en manos del contratista. ${ }^{6}$ Tal consideración resulta atinada con el tenor literal de los artículos 31 y 101 del Decreto 111 de 1996, que disponen que los rendimientos financieros de los dineros de los órganos que integran el presupuesto general de la nación le pertenecen a esta.

El anticipo, además, tiene por mandato legal una destinación específica, por lo que le está vedado al contratista destinarlos a un propósito distinto al contrato que debe ejecutar y, por ello, su inversión debe contar con un plan previamente definido.

De lo ya expresado merecen especial atención los siguientes hechos: i) la protección que se otorga a los recursos del anticipo, en el sentido de que estos constituyen un préstamo para el contratista y seguirán siendo de propiedad de la entidad contratante, y ii) la obligación del cumplimiento oportuno de los planes de inversión por parte de los contratistas para recibir el avance.

A continuación, se expondrá un análisis descriptivo del concepto del anticipo en el ordenamiento jurídico colombiano, sus principales características y los principales mecanismos con que cuenta el Estado para proteger estos recursos.

\section{Objetivo general}

Determinar si, conforme a la legislación vigente, la figura del anticipo en los contratos estatales es una institución segura y si cuenta con mecanismos de control efectivos frente a contratistas incumplidos o corruptos.

\subsection{Objetivos específicos}

- Establecer los elementos característicos de la responsabilidad fiscal de los contratistas en cuanto al manejo de anticipos.

- Evaluar la efectividad de las medidas que pueden adoptar las entidades públicas respecto al manejo del anticipo, mediante la fiducia mercantil, en relación con sus contratistas y con la sociedad fiduciaria.

$6 \quad$ Luis Guillermo Dávila Vinueza, Régimen jurídico de la contratación estatal: aproximación crítica a la Ley 80 de 1993 (Bogotá: Legis, 2003), 412. 
- Identificar si el manejo del anticipo con la figura de la fiducia mercantil constituye una verdadera solución frente a los problemas de corrupción derivados del uso directo de los recursos por parte de los contratistas del Estado.

\section{Justificación}

Como quiera que el anticipo en los procesos de contratación estatal es una figura que pretende apoyar a los contratistas para el inicio de sus proyectos cuando estos no tienen el músculo financiero para comenzar a cumplir sus compromisos contractuales, es deber del Estado, por medio de las instituciones públicas, como lo dispone la Constitución Política, velar por el interés general y evitar detrimentos patrimoniales estatales o abusos en la elección y adjudicación de los contratos ${ }^{7}$ y, en esa línea, garantizar que los dineros entregados sean administrados en el objeto del contrato, lo cual implica el cumplimiento de un deber de vigilancia y control por parte de las entidades contratantes que los entregan.

Por lo anterior, se justifica hacer una revisión normativa, doctrinal y jurisprudencial, con el fin de determinar si se puede asignar una responsabilidad contractual derivada del incumplimiento del contrato estatal por el mal manejo de los anticipos y si los mecanismos existentes para mitigar el riesgo de un detrimento al patrimonio público por inadecuado manejo de los recursos públicos, producto de los anticipos, son efectivos a la hora de recuperar dineros en favor del Estado.

\section{Marco teórico analítico}

\subsection{La concepción del anticipo: los derechos y obligaciones asociados a la figura}

El anticipo se concibe como un giro parcial de recursos comprometidos en virtud de un contrato estatal, que la entidad contratante le hace a su contratista, con el fin de apalancar los costos asociados al inicio de la ejecución del objeto contratado. La figura no ha sido definida en la Ley, pues la regulación vigente se limita a prever que "en los contratos que celebren las entidades estatales se podrá pactar el pago

Harol Alexander Alarcón Quiroga, "Contratación estatal comparada con Argentina”, Novum Jus 4, núm. 1 (2010): 233, https://novumjus.ucatolica.edu.co/article/view/707/723 (acceso febrero 28, 2022). 
anticipado y la entrega de anticipos, pero su monto no podrá exceder del cincuenta por ciento (50\%) del valor del respectivo contrato". ${ }^{8}$

Por lo tanto, cabe recurrir a la jurisprudencia y la doctrina para comprender el término. Cubides lo define como el "mecanismo de financiación que les permite a los colaboradores de la Administración asumir los costos iniciales que se requieren para la ejecución del objeto contractual". ${ }^{9}$ Matallana, por su parte, señala que es "una retribución que se otorga en contratos de tracto sucesivo antes o paralelamente a la iniciación del contrato, y que va con destinación a cubrir sus costos iniciales". ${ }^{10}$

A su turno, la Contraloría General de la República sostiene que este es "la suma de dinero que se entrega al contratista para ser destinada al cubrimiento de los costos en que este debe incurrir para iniciar la ejecución del objeto contractual". ${ }^{11}$

Para el Consejo de Estado, se trata de:

[...] un adelanto, avance o primer pago del precio no causado para la iniciación del objeto contractual, los trabajos o servicios, la atención de los gastos preliminares y su aplicación a los fines del contrato, que sólo se incorporan al patrimonio del contratista e implican un pago en la medida de su amortización. ${ }^{12}$

Su regulación proviene de la facultad de las entidades de pactarlo en determinados contratos y se debe ejercer en consideración a la necesidad debidamente soportada de entregar unos recursos para apoyar al contratista en el adecuado cumplimiento de las obligaciones contractuales, sin exceder los límites fijados por la ley. Para Santofimio, ${ }^{13}$ el tope fijado por el Legislador para su reconocimiento es la única limitación de la ley respecto a la autonomía de la voluntad para el ejercicio de esta facultad.

8 República de Colombia, Congreso de la República, Ley 80 de 1993, "Por la cual se expide el Estatuto general de contratación de la Administración pública" (Bogotá: Diario Oficial núm. 41 094, 28 de octubre de 1993). art. 40 , parágrafo.

9 Jaime Cubides Cárdenas et al., "Derecho público en el siglo XXI: regulación del mercado, contratación pública y derechos humanos", colección JUS Derecho Público, núm. 15 (Bogotá: Universidad Católica de Colombia, 2016), 44.

10 Matallana Camacho, Manual, 855.

11 República de Colombia, Contraloría General de la República. "Concepto Jurídico No 7461".

12 República de Colombia, Consejo de Estado, Sala de lo Contencioso Administrativo, Sección Tercera, Sentencia del 13 de septiembre de 1999.

13 Jaime Orlando Santofimio Gamboa, Tratado de derecho administrativo, Tomo IV: Contratación indebida (Bogotá: Universidad Externado de Colombia, 2004), 374-375. 
Por lo tanto, se trata de una figura producto de un acuerdo de voluntades que crea derechos y obligaciones para ambas partes.

Desde la perspectiva de la entidad pública, el pacto del anticipo supone la obligación de entregar los dineros que lo integran, de la que se deriva el derecho correlativo de recibirlos que le asiste al contratista, previa constitución de la garantía.

La referida correlatividad se invierte a partir de la entrega de los recursos, puesto que, desde ese momento, surgen para el contratista obligaciones, de las que emanan derechos a favor de la entidad estatal:

- El contratista debe invertir los recursos en la ejecución del objeto y de las obligaciones contractuales.

- El contratista debe pagar, por medio de la amortización, el valor del anticipo recibido, hasta llegar a la amortización total.

- La entidad, a su turno, tiene derecho de recibir, por concepto de amortización, el valor girado anticipadamente.

- La entidad tiene derecho, si así se requiere, de hacer efectiva la garantía de cumplimiento, en el amparo correspondiente al buen manejo y a la correcta inversión del anticipo, cuando evidencie que el contratista incurre en conductas que impliquen mal manejo o incorrecta inversión de los dineros del Estado.

El carácter correlativo de los derechos y las obligaciones referidos habilita el ejercicio de determinadas acciones o la presentación de reclamaciones por parte de la entidad contratante o del contratista.

Por ejemplo, en el caso del contratista, podría acudir a excepción de contrato no cumplido cuando la entidad incumpla su deber de girar oportunamente el anticipo al que se ha comprometido, siempre y cuando su omisión o tardanza en el pago incida de manera grave y determinante en la inacción del contratista. Así lo ha reconocido el Consejo de Estado:

Se permite con un tratamiento restringido la exceptio non adimpleti contractus (art. 1609 del C. C.), como regla de equidad en los contratos de los que se derivan obligaciones correlativas para ambas partes y que resulta aplicable en 
el ámbito de la contratación estatal por remisión del artículo 13 de la Ley 80 de 1993, pero que, en aras de armonizar la prevalencia del interés público o la continuidad del servicio público con el interés jurídico del particular, no tiene el alcance amplio de que goza en la contratación entre particulares, sino que en el contencioso administrativo contractual está limitada únicamente a aquellos eventos en que el incumplimiento imputable a la entidad pública sea grave, serio, determinante, trascendente y de gran significación, de manera que sitúe al contratista en una razonable imposibilidad de cumplir sus obligaciones, siendo en ese caso procedente que este la pueda alegar y suspender el cumplimiento de sus obligaciones. ${ }^{14}$

Sobre el particular, en sentencia más reciente, la misma Corporación expresó que la exceptio non adimpleti contractus solo tiene cabida en casos en los que se demuestre la ocurrencia de las situaciones identificadas en la jurisprudencia para considerar que el incumplimiento de la entidad contratante es grave y determinante. En esta oportunidad señaló:

3.5.1.1. Anticipo: la improcedencia de la "excepción de contrato no cumplido".

[...] El contratista solo puede suspender la ejecución del contrato cuando pruebe los supuestos de la excepción de contrato no cumplido, esto es, cuando demuestre que ese incumplimiento de la Administración es grave y determinante de la inacción del contratista. ${ }^{15}$

Este tema ha sido abordado en múltiples ocasiones por la Sección Tercera del Consejo de Estado y recientemente resumido por la Sala en estos términos:

Señala el artículo 1609 del Código Civil que en los contratos bilaterales ninguno de los contratantes está en mora dejando de cumplir lo pactado, mientras el otro no lo cumpla por su parte, o no se allana a cumplirlo en la forma y tiempo debidos". Sobre el precepto anterior la doctrina y la jurisprudencia han pretendido edificar la figura de la excepción de contrato no cumplido - exceptio non adimpleti contractus - la cual tuvo su génesis en el derecho privado, pero que será procedente en materia de contratos estatales única y exclusivamente

14 República de Colombia, Consejo de Estado, Sala de lo Contencioso Administrativo, Sección Tercera, Sentencia del 31 de enero de 1991, Radicado 4739, M. P. Julio César Uribe Acosta.

15 República de Colombia, Consejo de Estado, Sala de lo Contencioso Administrativo, Sección Tercera, Subsección C, Sentencia del 9 de julio de 2018, Expediente 42 171, C. P. Jaime Enrique Rodríguez Navas. 
cuando del incumplimiento de la Administración se genere una razón de imposibilidad de cumplir para la parte que se allane a ejecutar la prestación debida, pues un principio universal de derecho enseña que a lo imposible nadie está obligado. En los demás eventos, como regla general, el contratista estará obligado a cumplir las obligaciones, así se presente incumplimiento que no impida la ejecución. Tal postura se basa en la aplicación de cuatro fundamentos, a saber: que se trate de contratos sinalagmáticos, que el incumplimiento de la administración sea cierto o real, que tenga una gravedad ostensible y considerable que imposibilite el incumplimiento, y que quien la invoca no haya dado lugar al incumplimiento de la otra. ${ }^{16}$

Así las cosas, aunque con un carácter restringido, la omisión o el retardo en el pago del anticipo al que se ha comprometido la entidad estatal puede dar lugar a la no ejecución del contrato justificada por parte del contratista, lo que denota la importancia de que el Estado honre los compromisos que asumió en relación con esta figura, ya que, en determinadas circunstancias, el no pago o el atraso puede afectar tanto el interés público, por la inejecución del objeto contractual, como el patrimonio económico, en el evento en que, alegada la excepción por el contratista, el juez competente la estime procedente y ordene el pago de los perjuicios que se deriven del incumplimiento.

Dada la importancia jurídica que tiene el anticipo como dinero público, la entidad contratante debe garantizar la vigilancia permanente de estos y de la forma como se invierten; por tanto, tiene el deber de acudir a los mecanismos legales o pactados en el contrato, para exigir el buen manejo y la correcta disposición del anticipo.

Una de las herramientas con las que cuenta para hacerlo es la consagración, en las estipulaciones contractuales, de la obligación del contratista de presentar planes de inversión de ese recurso, como medida preventiva para su buen uso. El detalle en esos planes les permite a las entidades públicas hacer un seguimiento más preciso y adoptar medidas más efectivas cuando la ejecución del dinero no se apega al plan allí definido.

Ahora bien, la inclusión de una cláusula de ese tenor no es un deber que se deriva de la ley; en la práctica, suele ocurrir que la exigencia de dicho plan se presente

16 República de Colombia, Consejo de Estado, Sala de lo Contencioso Administrativo, Sección Tercera, Subsección C, Sentencia del 9 de julio de 2018. 
como un requerimiento por la interventoría o la supervisión. Cuando así sucede, la entidad pública queda desprovista de la opción de acudir a una declaratoria de incumplimiento de contrato y la adopción de las medidas asociadas a la misma, pues el plan y su contenido no forman parte del alcance obligacional del contrato. Por lo tanto, lo recomendable es insertar la obligación de presentar el plan de inversión del anticipo y estipular que este forma parte integral del contrato. Así, en este último evento, de incumplir el plan de inversión, se estaría en presencia de un verdadero incumplimiento contractual, que habilitaría el inicio del procedimiento consignado en el artículo 86 de la Ley 1474 de 2011 y la adopción de las medidas asociadas a este, previstas en la ley para proteger los intereses y recursos del Estado, como la imposición de multas, la declaratoria de incumplimiento, la efectividad de la cláusula penal y la de las garantías otorgadas por el contratista, como mecanismos propios del proceso administrativo sancionatorio contractual. ${ }^{17}$

Otra herramienta con la que cuenta la entidad pública para el correcto ejercicio de su deber de vigilancia y seguimiento a los recursos entregados a título de anticipo es la incorporación, en el texto del contrato, de la obligación del contratista de constituir la garantía única de cumplimiento, que abarque el amparo de buen manejo y correcta inversión. Esta, a diferencia del plan de inversión, no es preventiva, sino paliativa y se deriva de lo previsto en la ley, lo que denota que la exigencia de la garantía no es un asunto del que pueda prescindirse cuando se ha pactado un anticipo. En efecto, el deber de exigir la constitución de la garantía resulta de lo previsto en el artículo 7 de la Ley 1150 de 2007, que regula aquella obligación de los contratistas de constituir garantías que amparen las prestaciones que asumen en el contrato y el deber de las entidades públicas de exigirlas.

Así mismo, el artículo 2.2.1.2.3.1.7 del Decreto 1082 de 2015 prevé que la garantía de cumplimiento debe conllevar, entre otros aspectos y cuando así se requiera, el amparo de buen manejo y correcta inversión del anticipo, que cubre los perjuicios sufridos por la entidad estatal con ocasión de: i) la no inversión del anticipo; ii) el uso indebido del anticipo, y iii) la apropiación indebida de los recursos recibidos en calidad de anticipo.

Pactada la obligación de constituir la garantía con el amparo referido, si la entidad advierte que concurre cualquiera de las circunstancias descritas en el párrafo anterior, esta puede acudir al procedimiento fijado en el artículo 86 de la Ley 1474 de 2011

17 República de Colombia, Corte Constitucional, Sentencia T-569 de 8 de octubre de 1998, M. P. Alfredo Beltrán Sierra. 
para declarar el siniestro y hacer efectiva la garantía, trámite dentro del cual deberá observar el debido proceso. ${ }^{18}$

Sobre el punto conviene precisar que, en Colombia, por regla general, la declaratoria de responsabilidad corresponde al Poder Judicial y no a las partes en conflicto. Sin embargo, señala Sierra:

[...] por ser parte en los contratos estatales una entidad pública, no siempre será necesario acudir al juez del contrato para que declare la responsabilidad de uno de los sujetos y, por ende, para que sean exigibles los perjuicios derivados de ella. ${ }^{19}$

Así, el adecuado cumplimiento del deber de vigilancia y seguimiento a la ejecución contractual, si se han entregado anticipos, requiere: i) revisar y aprobar el plan de inversión del anticipo y controlar su buen manejo en concordancia con las obligaciones que para dicho manejo se establezcan en la ley y en el contrato, con los soportes que sean necesarios; ii) vigilar el correcto manejo de los anticipos pactados en los contratos, y iii) controlar la inversión y la amortización oportuna del anticipo entregado al contratista de conformidad con lo pactado en la orden contractual o contrato.

Además de las herramientas ya descritas y para cierto tipo de contratos, entre estos el contrato de obra, el Legislador ha previsto la obligación del contratista de constituir un patrimonio autónomo, mediante contrato de fiducia mercantil, para el manejo de los recursos que recibe a título de anticipo. La relevancia de esta figura respecto a cierto tipo de contratos, como los asociados a infraestructura, ya la habían advertido Benavides ${ }^{20}$ y Galofre ${ }^{21}$ con antelación a la expedición de la norma.

18 Juan Manuel Laverde Álvarez, Manual de procedimiento administrativo sancionatorio, 2a ed. (Bogotá: Legis, 2018), 36.

19 Santiago Sierra Ospina, "El anticipo en el contrato estatal: generalidades y mecanismos de protección" (Tesis de pregrado, Universidad Pontificia Bolivariana, 2011), 42.

20 Juan Benavides, "Public Contracts and Institutional Weakness in Infrastructure in Colombia", Revista de Ingeniería, núm. 32 (2010): 5, http://www.scielo.org.co/scielo.php?script=sci_abstract\&pid=S0121$49932010000200012 \& \operatorname{lng}=e n \& n r m=i s \& t \operatorname{lng}=e n$ (acceso agosto 25, 2021).

21 Paula Andrea Galofre Amín, "El esquema fiduciario en la contratación estatal, su aplicación en el contrato de concesión infraestructura vial: el manejo de los recursos de la concesión a través del negocio fiduciario" (Tesis de maestría, Universidad Externado de Colombia, 2006), 12. 
En efecto, el artículo 91 de la Ley 1474 de 2011 dispone:

[...] en los contratos de obra, concesión, salud o los que se realicen por licitación pública, el contratista deberá constituir una fiducia o un patrimonio autónomo irrevocable para el manejo de los recursos que reciba a título de anticipo, con el fin de garantizar que dichos recursos se apliquen exclusivamente a la ejecución del contrato, salvo que este sea de menor o mínima cuantía (cursivas propias). ${ }^{22}$

Se trata, entonces, de una obligación que el Legislador impone a los contratistas del Estado y no a las entidades públicas. Las particularidades sobre el cumplimiento de esta obligación están definidas en el artículo 2.2.1.1.2.4.1 del Decreto 1082 de 2015.

El texto de la norma citada expresa que el contrato que debe celebrar el contratista para el manejo de los recursos del anticipo es el de fiducia mercantil, con lo cual califica la previsión general de la ley, respecto a que el manejo de los recursos del anticipo debe hacerse por medio de una fiducia o un patrimonio autónomo. Así mismo, la disposición reglamentaria establece que los recursos entregados a título de anticipo dejarán de ser parte del patrimonio de la entidad y conformarán un patrimonio autónomo.

La obligación que se consagra en estas disposiciones tiene como fin garantizar que los recursos entregados a título de anticipo en los contratos se destinen a la ejecución del objeto y las obligaciones del respectivo contrato estatal. ${ }^{23}$

Así mismo, la finalidad con la cual fue consagrada la obligación en cuestión muestra que de ninguna manera el contratista, que sería el constituyente de la fiducia, podría actuar como fiduciario, pues en la exposición de motivos del proyecto de ley que dio lugar a la expedición y sanción de la Ley 1474 de 2011 se advierte que lo pretendido es evitar que los recursos del anticipo sean manejados directamente por los contratistas.

Además, el artículo 91 de la Ley 1474 de 2011 consagra expresamente que la fiducia o el patrimonio autónomo generarán una comisión fiduciaria y que su pago

22 República de Colombia, Congreso de la República, Ley 1474 de 2011, "Por la cual se dictan normas orientadas a fortalecer los mecanismos de prevención, investigación y sanción de actos de corrupción y la efectividad del control de la gestión pública" (Bogotá: Diario Oficial núm. 48 128, 12 de julio de 2011), art. 91.

23 República de Colombia, Contraloría General de la República, "Concepto Jurídico 2015EE0054117. Mayo 4 de 2015”, https://vlex.com.co/vid/concepto-n-cgr-oj-797797673 (acceso agosto 25, 2021). 
estará a cargo del contratista, con lo cual queda claramente previsto que los gastos que se originan por acudir a la referida figura no deben asumirse como un valor adicional al del contrato.

La fiducia mercantil está definida en el Código de Comercio en los siguientes términos:

Es un negocio jurídico en virtud del cual una persona, llamada fiduciante o fideicomitente, transfiere uno o más bienes especificados a otra, llamada fiduciario, quien se obliga a administrarlos o enajenarlos para cumplir una finalidad determinada por el constituyente, en provecho de este o de un tercero llamado beneficiario o fideicomisario. ${ }^{24}$

Con fundamento en lo dispuesto en la norma citada, se ha definido doctrinalmente que uno de los elementos esenciales de la fiducia mercantil, como negocio fiduciario, es el referido a la transferencia del derecho de dominio sobre los bienes objeto del contrato de fiducia. En ese sentido, se ha dicho que "la fiducia mercantil es un título traslaticio del derecho real de dominio o propiedad de los bienes fideicomitidos, en virtud del cual este pasa del fideicomitente al patrimonio autónomo, cuyo vocero es el fiduciario. ${ }^{25}$

Para concretar el alcance de la exigencia legal y reglamentaria que ya se han referido, resulta pertinente insistir en que la fiducia que debe constituirse es, por mandato normativo, una fiducia mercantil y que no se trata de una fiducia pública, por cuanto en esta no se crea un patrimonio autónomo al que se transfiere la propiedad de los bienes que lo integran y solo se configura cuando el fideicomitente es una entidad estatal y, como se dijo, en este caso, quien tiene la obligación de constituir la fiducia es el contratista. ${ }^{26}$

Para De la Torre, la fiducia pública fue creada por el artículo 32 de la Ley 80 de 1993, que difiere de la ya existente figura de fiducia mercantil, aunque, como lo indica la misma ley, a la fiducia pública le serán aplicables las normas del Código

24 República de Colombia, Presidencia de la República, Decreto 410 de 1971, "Por el cual se expide el Código de Comercio" (Bogotá: Diario Oficial núm. 33 339, 16 de junio de 1971), art. 1226.

25 Superintendencia Financiera de Colombia, "Circular Básica Jurídica (Circular Externa 007 de 1996)", https:// vlex.com.co/vid/circular-externa-basica-juridica-398669581 (acceso agosto 25, 2021).

26 Corte Constitucional, al analizar la constitucionalidad del artículo 32 de la Ley 80 de 1993, sobre el contrato de fiducia pública. 
de Comercio sobre fiducia mercantil, en cuanto sean compatibles con lo dispuesto en esta Ley. ${ }^{27}$

Sobre la fiducia pública y el encargo fiduciario público, es pertinente traer a colación lo expresado por la Corte Constitucional al analizar la constitucionalidad del artículo 32 de la Ley 80 de 1993, sobre el contrato de fiducia pública:

El Estatuto General de Contratación Administrativa creó un nuevo tipo de contrato, sin definirlo, denominado "fiducia pública", el cual no se relaciona con el contrato de fiducia mercantil contenido en el Código de Comercio. Se trata, pues, de un contrato autónomo e independiente, más parecido a un encargo fiduciario que a una fiducia (por el no traspaso de la propiedad, ni la constitución de un patrimonio autónomo), al que le serán aplicables las normas del Código de Comercio sobre fiducia mercantil, "en cuanto sean compatibles con lo dispuesto en esta ley [...]". 28

En efecto, en tanto la constitución de la fiducia es, por expreso mandato del artículo 91 de la Ley 1474 de 2011, reglamentada en el artículo 2.2.1.1.4.1. del Decreto 1082 de 2015, una obligación del contratista, esto es, del particular colaborador de la Administración pública, la celebración de un contrato de fiducia para dar cumplimiento a la norma referida no podría regirse por las especiales condiciones de la fiducia pública, en tanto que esta, como se advierte en el artículo 32 de la Ley 80 de 1993, fue concebida como un tipo especial de contrato estatal, esto es, como un contrato en el que una de sus partes es una entidad pública ${ }^{29}$ y en el que, como lo explica Díaz, ${ }^{30}$ los recursos se entregan a título de mera tenencia.

Por lo tanto, se impone concluir que el cumplimiento de la obligación contenida en el artículo 91 de la Ley 1474 de 2011, referida a que el contratista debe constituir una fiducia o un patrimonio autónomo para el manejo de los recursos que le son

27 David de la Torre Vargas, "Régimen jurídico de los contratos celebrados por el gestor en los planes departamentales de agua", Revista Digital de Derecho Administrativo, núm. 5 (2011): 133 y 139, https:// revistas.uexternado.edu.co/index.php/Deradm/article/view/2956 (acceso agosto 25, 2021).

28 República de Colombia, Congreso de la República, Ley 80 de 1993, art. 32.

29 Superintendencia Financiera de Colombia, "Circular Básica Jurídica (Circular Externa 007 de 1996)", https:// vlex.com.co/vid/circular-externa-basica-juridica-398669581 (acceso agosto 25, 2021).

30 Enrique Díaz, "Publicidad y oponibilidad de la fiducia mercantil en garantía" en Estudios de derecho privado, coord. Alejandro Venegas, Juan Pablo Cárdenas y Fabricio Mantilla, Tomo I (Bogotá: Universidad del Rosario, 2009). 332. 
entregados a título de anticipo, está sometido a lo previsto para ello en la normatividad comercial y financiera relacionada con la institución de la fiducia mercantil.

Ahora bien, no puede perderse de vista que el artículo 91 de la Ley 1474 de 2011 desconoce que tanto la doctrina como la jurisprudencia han señalado reiteradamente que la titularidad de los recursos que se entregan por las entidades estatales contratantes al contratista a título de anticipo es de aquellas, pues se obliga al particular a constituir una fiducia, que lleva implícito, como se ha expuesto, la transferencia de dominio de dichos recursos, es decir, se le impone la obligación de transferir la titularidad de unos bienes que no son suyos. ${ }^{31}$

Cabe considerar el papel que desempeñan las sociedades fiduciarias en los negocios donde se administran y gestionan recursos públicos, pues los negocios fiduciarios constituyen un mecanismo de transparencia en los negocios donde están involucradas, de una u otra forma, las entidades estatales. Así lo demuestra la expedición de la Ley 1474 de 2011 y su exposición de motivos, en los siguientes términos:

Se ha identificado, que con frecuencia los contratistas no aplican los anticipos a la ejecución del contrato, situación que finalmente produce el incumplimiento de las obligaciones o la entrega extemporánea de las obras. Por ello, se establece un sistema de seguimiento a los anticipos imponiendo la obligación del contratista de constituir una fiducia irrevocable con lo que reciba de los mismos, para que sea esta la que garantice que tales recursos se aplicarán exclusivamente a la ejecución del contrato. ${ }^{32}$

Con base en el diseño que el Legislador le dio a la figura, la doctrina ha considerado que la entrega de los recursos que integran el anticipo no supone un cambio en la naturaleza de los mismos, en cuanto la fiduciaria los recibe como un aporte ${ }^{33}$ de su fideicomitente. Conforme a esta interpretación, aunque los recursos salen directamente del presupuesto de la entidad estatal, no por esto cambian su naturaleza

31 República de Colombia, Corte Suprema de Justicia, Sala de Casación Civil, Sentencia del 3 de agosto de 2005, Expediente 1909, M. P. Silvio Fernando Trejos Bueno.

32 República de Colombia, Senado de la República, Proyecto de Ley 142 de 2010, "Proyecto de ley por el cual se dictan normas orientadas a fortalecer los mecanismos de prevención, investigación y sanción de actos de corrupción y la efectividad del control de la gestión pública" (Bogotá: Gaceta del Congreso núm. 607, 6 de septiembre de 2010).

33 Vale aclarar que quien entrega los recursos del anticipo a la fiduciaria es directamente la entidad estatal; sin embargo, dado que esta aparece en el contrato fiduciario como beneficiaria y no como fideicomitente, el contrato de fiducia crea una ficción, en el sentido de indicar que la fiduciaria recibe estos recursos a título de aporte por parte del fideicomitente (contratista). 
jurídica, pues solamente se convierten en recursos privados en proporción a su amortización.

Esta lectura, por lo demás, es acorde con la finalidad de la figura, en tanto se ajusta al propósito perseguido por esta, que es garantizar que la ejecución y la disposición de los recursos no dependa solo del contratista y permita el ejercicio de las competencias de los órganos de control fiscal, frente a los recursos que integran el anticipo.

\section{Responsabilidades derivadas de las cláusulas que regulan el anticipo}

Al elaborar un contrato es necesario determinar las reglas a las que las partes se van a someter, esto es, fijar las cláusulas que definen el alcance del negocio jurídico. Estas cláusulas forman parte de las herramientas con las que cuenta el Estado para verificar, corregir y sancionar a los contratistas que no cumplen con sus obligaciones. La aplicación de las cláusulas busca cumplir con un fin especial que se le impone al Estado mediante el artículo 2 de la Constitución Política y que no es otro que proteger el interés público y los fines esenciales del Estado.

Por lo anterior, cuando el contratista infringe alguna de las estipulaciones contractuales que lo vinculan, el Estado puede ejercer su potestad sancionatoria, la cual se deriva de la gestión de los intereses colectivos que son encomendados a cada entidad pública, ya que esta se articula con las funciones y las competencias, así como las responsabilidades que tiene la entidad en cuanto a la dirección de los contratos.

Respecto a la obligación del contratista de cumplir las cláusulas pactadas y aceptadas dentro del contrato estatal, en particular las que se refiere a la figura del anticipo, es preciso señalar que esta debe estar taxativamente señalada y debe especificar el porcentaje que la entidad pagará al contratista por este rubro, la forma como se ha de realizar este desembolso y su amortización.

No hay una disposición taxativa que disponga en qué contratos es obligatorio pactar la entrega de un anticipo o en cuáles no; lo único que regula es el monto máximo que puede alcanzar y la constitución de la garantía para amparar el riesgo que se derive de su mal manejo. 
[...] las demás obligaciones que se establezcan en relación con el anticipo serán fruto de la autonomía de la voluntad, sin perjuicio de los controles y responsabilidades que pesan sobre los servidores públicos y particulares involucrados en la entrega y recibo de anticipos. ${ }^{34}$

Respecto al manejo y a la inversión del anticipo, afirma González, que esta "es quizá una de las obligaciones contractuales cuyo incumplimiento puede causar más responsabilidades adicionales a la responsabilidad civil para los sujetos que intervienen en esta actividad". ${ }^{35} \mathrm{El}$ mal manejo del anticipo puede constituir un incumplimiento que implique responsabilidad contractual, pero, además, puede dar lugar a la comisión de delitos y a un detrimento patrimonial del Estado, es decir, conllevar responsabilidad penal y fiscal y, eventualmente, disciplinaria.

Acerca del incumplimiento de la entidad estatal en su deber de entregar el anticipo en la oportunidad, el tiempo y la forma que se hayan previsto en el contrato, surge una responsabilidad contractual derivada de la no entrega o entrega tardía. Se presume para la entidad la obligación de restablecer el equilibrio económico del contrato e indemnizar los demás perjuicios causados con su incumplimiento al contratista. ${ }^{36}$

Es necesario que, entre las cláusulas contractuales, se pacten las consecuencias derivadas de los eventos en que se incumpla el plan de manejo del anticipo, so pena de la posibilidad que tiene la Administración de imponer una sanción contractual, bien sea una multa o una declaratoria de incumplimiento, consecuencia apenas lógica de lo ya explicado, según lo cual todo lo relativo a las obligaciones contractuales del anticipo se derivan principalmente del contrato, para lo cual deben tenerse presentes tres aspectos: i) la forma en la que se puede incumplir el plan de manejo del anticipo; ii) el principio de legalidad y tipicidad por el incumplimiento, y iii) los perjuicios ocasionados a la entidad contratante y si es posible hablar de un incumplimiento sin perjuicio para la entidad estatal. ${ }^{37}$

34 Cristina González Duarte. "El anticipo en el contrato estatal: concepto, derechos, obligaciones y responsabilidades asociadas" (Tesis de pregrado, Universidad Eafit, 2011), 26.

35 González Duarte, "El anticipo", 26.

36 República de Colombia, Congreso de la República, Ley 80 de 1993, art. 50.

37 Diana Lorena Mateus Londoño, "Debido proceso probatorio en el procedimiento sancionatorio contractual en Colombia", Revista digital de derecho administrativo, núm. 24, (2020): 188. 


\section{Análisis de la eficacia de los mecanismos de control para proteger los dineros públicos objeto de anticipo en los contratos estatales}

Entre los mecanismos que tiene el Estado respecto al incumplimiento del contratista en el manejo de los anticipos, la entidad puede calificar el comportamiento contractual del contratista como incumplido y cuantificar los perjuicios sufridos mediante acto administrativo. Además, tiene la posibilidad de buscar, vía acción de controversias contractuales, la reparación integral de los perjuicios ocasionados por el incumplimiento de las obligaciones del manejo del anticipo acudiendo al juez del contrato. ${ }^{38}$

Disciplinariamente, en tanto el particular-contratista recibe un bien público, a la luz de las normas que regulan el derecho disciplinario, ${ }^{39}$ adquiere la calidad de sujeto disciplinable y, por tanto, receptor de las sanciones consagradas en el Estatuto único disciplinario.

Penalmente, existe también una responsabilidad para los particulares vinculados contractualmente con la Administración; sin embargo, para que se pueda equiparar la responsabilidad del particular a la de servidor público, el primero debe asumir el ejercicio de una función pública. La Corte Constitucional explica que es posible que, en consideración al particular objeto de cada contrato, el contratista asuma el ejercicio de funciones públicas de manera excepcional, caso en el cual se tendrá como un servidor público para efectos de la responsabilidad penal. ${ }^{40}$

Por lo anterior, se puede endilgar un tipo penal al contratista incumplido, el cual se podría enmarcar en una conducta típica de apropiación del anticipo, pues cabe la posibilidad de dar aplicación tanto al peculado por apropiación como al abuso de confianza, siempre que se cumpla el requisito indispensable de que el particular ejerza, parcial o totalmente, una función pública.

38 República de Colombia, Congreso de la República, Ley 1150 de 2007, "Por medio de la cual se introducen medidas para la eficiencia y la transparencia en la Ley 80 de 1993 y se dictan otras disposiciones generales sobre la contratación con recursos públicos" (Bogotá: Diario Oficial núm. 46 691, 16 de julio de 2007), art. 17; Ley 1474 de 2011, art. 86.

39 República de Colombia, Congreso de la República, Ley 734 de 2002, "Por la cual se expide el Código Disciplinario Único" (Bogotá: Diario Oficial núm. 44 708, 13 de febrero de 2002), art. 53.

40 República de Colombia, Corte Constitucional, Sentencia C-563 de 7 de octubre de 1998, M. P. Antonio Barrera Carbonell y Carlos Gaviria Díaz. 
En cuanto a la responsabilidad fiscal, la Constitución Política define el control fiscal como la función pública ejercida por la Contraloría General de la República, como ente de vigilancia de la Administración y de los particulares o entidades que manejen fondos o bienes de la nación (art. 267). De este artículo superior se desprende la promulgación de la Ley 610 de 2000, que define el procedimiento mediante el cual se adelantan los procesos de control fiscal y constituye el conjunto de actuaciones tendientes a determinar la responsabilidad de particulares o entidades públicas que, en ejercicio de la gestión fiscal o con ocasión de ella, causan, por acción u omisión, un daño patrimonial al Estado. Así las cosas, mediante el juicio de responsabilidad fiscal se busca el resarcimiento del erario que ha sido afectado con la actuación del presunto responsable fiscal, con la imposición de una sanción pecuniaria, como mecanismo de recuperación del dinero. ${ }^{41}$

Entonces, por consagración legal, existen distintos mecanismos que permiten exigir al contratista una correcta inversión y un buen manejo del anticipo que se le entrega durante la ejecución de un contrato estatal. Algunos tienen carácter preventivo, como serían la exigencia contractual del plan de inversión del anticipo y la efectiva vigilancia y el seguimiento a su cumplimiento, y otros revisten naturaleza compensatoria o resarcitoria, cuando se ha materializado el riesgo por el indebido manejo y la incorrecta inversión de los recursos que constituyen el anticipo, como serían las declaratorias de incumplimiento, la correspondiente efectividad de la garantía única de cumplimiento en el amparo de buen manejo y correcta inversión y las reclamaciones judiciales o administrativas de las sumas de dinero respectivas, así como las acciones dirigidas a establecer la responsabilidad civil, penal, disciplinaria y fiscal del contratista y de los funcionarios que hubieran dado lugar a la afectación del patrimonio público y, eventualmente, la de la compañía aseguradora, como tercero civilmente responsable. ${ }^{42}$

Ahora bien, en cuanto se refiere a la responsabilidad fiscal, se considera que las decisiones adoptadas sobre esta constituyen un insumo importante para evaluar la eficacia de algunos de los mecanismos consagrados en la ley como herramientas para que las entidades públicas protejan los recursos otorgados a título de anticipo. Así, con el ánimo de validar su aplicación y las medidas concretas que han permitido

$41 \quad$ Ligia Helena Borrero Restrepo, "El control fiscal a la gestión fiscal de los particulares que manejan fondos y bienes públicos, 2011". https://www.contraloria.gov.co/documents/20181/257118/Control+Fiscal+a+Particulares. pdf/b3f22d60-8bef-439b-9caf-bacbf694e699?version=1.0 (acceso agosto 25, 2021).

42 República de Colombia, Consejo de Estado, Sala de lo Contencioso Administrativo, Sección Primera, Sentencia del 23 de agosto de 2019, Expediente 2001-23-31-000-2012-00047-011, C. P. Hernando Sánchez. 
adoptar, se analizarán decisiones de la Contraloría General de la Republica respecto al mal manejo de los anticipos por parte de contratistas del Estado.

Como elementos probatorios necesarios para la demostración del hallazgo fiscal se requieren, por ejemplo: el contrato principal con sus adiciones, modificaciones, otrosíes y prórrogas; las actas parciales y de liquidación; la póliza que garantiza el adecuado manejo del anticipo; el recibo de consignación donde conste el pago de los rendimientos; la certificación de la cuenta para el manejo del anticipo; las cuentas por pagar; los saldos por legalizar y los informes de interventoría o supervisión, entre otros. Estos elementos, si bien pueden ser suficientes para la formulación de hallazgos, no lo son necesariamente para establecer responsabilidad fiscal.

Precisado lo anterior, se examinarán las decisiones que servirán de insumo para las conclusiones del presente estudio.

El primero es un fallo de la Contraloría General de la República tras una investigación realizada sobre el departamento de Casanare, en la cual se encontró que el contratista hizo un mal manejo de los recursos del anticipo. La Contraloría halló que el departamento de Casanare y la empresa contratista Junta de Vivienda Santo Domingo, celebraron un convenio asociativo de vivienda, cuyo objeto era la construcción de 304 unidades de vivienda de interés social en el municipio de Yopal.

El valor del convenio fue de \$ 9998800 000. Se determinó, mediante informe técnico, que:

[... el el valor girado sin descuentos al contratista por concepto de anticipo fue \$2 228000 000, que no se reflejan en la construcción del proyecto, y que analizados desde el punto de vista porcentual no alcanza el cero por ciento de ejecución. ${ }^{43}$

Se concluyó que el daño ocasionado en los recursos patrimoniales del departamento de Casanare correspondió al mal manejo del anticipo por parte de la sociedad contratista, la cual recibió el 50 \% del valor total de los recursos aportados por el departamento para el desarrollo del proyecto Torres de Santo Domingo, pero no ejecutó obra alguna.

43 República de Colombia, Contraloría General de la República, "Auto ORD-80112-0250-2018. Noviembre 02 de 2018 en el PRF 80853-266-03677". 
Producto de lo anterior, la Contraloría coligió que se evidenciaba una gestión fiscal directa ineficaz, ineficiente y antieconómica por parte de la coordinadora del grupo gestor para el desarrollo de los planes y programas de vivienda en Casanare y la gobernadora encargada de ese departamento, pues con su actuar permitieron que los recursos entregados en calidad de anticipo, destinados a la ejecución del Convenio 0082 de 26 de noviembre de 2010, se perdieran, al igual que la empresa contratista, como gestor fiscal directo, respecto al manejo del anticipo; por tal razón, la Contraloría dictó fallo con responsabilidad fiscal al contratista y al interventor.

En estas investigaciones, el alcance de las decisiones de la Contraloría se extiende a todos los actores; así, en ocasiones se observan fallos en contra de las interventorías, como en el caso analizado, pues se comprobó que la conducta negligente y omisiva del interventor permitió que los recursos del anticipo destinados para la ejecución de las obras relacionadas con el referido convenio no tuvieran un adecuado control, dado que la labor de verificación nunca fue desarrollada por este. De allí que se tuviera que declarar el incumplimiento del Contrato 1328 de 2010 por parte de la Gobernación de Casanare.

El segundo evento en estudio corresponde a la decisión adoptada mediante Auto 0015 del 19 de enero de 2019, por el cual se decidió el grado de consulta contra el auto proferido en el proceso 6-031-2013, en el que se decidió archivar el proceso de responsabilidad fiscal adelantado por la incompleta amortización del anticipo, en cuantía de \$ 3890206 234,38, en relación con el Contrato 1657 de 2005, suscrito por el Invías con el Consorcio Proyectar, cuyo objeto fue:

El diseño, reconstrucción, pavimentación y/o repavimentación de la vía grupo 44 tramo 1 Hinche-La Peña-paso El Rejo-Nimaima-Nocaima-autopista Medellín paso de Rejo-Tobia-autopista Medellín del KO+000 al K17+360; del K23+070 al K33+460; del K34+500 al K36+750, con una longitud de 30 kilómetros, y tramo 2 Nocaima-Vergara del K7+200 al K12+760, con una longitud de 5,56 kilómetros en el departamento de Cundinamarca. ${ }^{44}$

En esta oportunidad, la Contraloría General de la República encontró ajustada la decisión, en tanto la entidad contratante, previa declaratoria de incumplimiento del contrato, tuvo que acudir a la vía judicial (proceso ejecutivo) para reclamar las

44 República de Colombia, Contraloría General de la República, "Auto 0015 del 19 de enero de 2019. PRF. 2013 IE 012015316-031-13/6-031-13". 
sumas de dinero correspondientes al anticipo no amortizado, circunstancia que impedía la declaratoria de responsabilidad fiscal, pues no se tenía certeza sobre el daño al patrimonio público. De las consideraciones expresadas en esa ocasión, se resalta que, para la Contraloría, la incompleta amortización del anticipo ocurrió, pese a que tanto la interventoría como la entidad afectada (Invías) adelantaron todas las gestiones previas necesarias para lograr el pago de la amortización del anticipo, porque declararon el siniestro y, por último, demandaron ejecutivamente al contratista para lograr la devolución de los dineros girados como anticipo y que no fueron amortizados.

La tercera decisión objeto de análisis corresponde al Auto 002 del 4 de enero de 2019, por medio del cual se resolvió el grado de consulta en contra del fallo con responsabilidad fiscal 015 del 2 de octubre de 2018, proferido en el proceso 6-057-2013, PRF 2014-3374, cuya entidad afectada es el Invías.

En el auto en cuestión se confirmó la decisión de declarar responsable fiscalmente al contratista por la no amortización completa del anticipo entregado en virtud del Contrato 1255/2006, celebrado entre el Invías y la Unión Temporal BOM, cuyo objeto fue el mejoramiento y el mantenimiento de la carretera Río Pereira-San Juan del Cesar-Buenavista, Ruta 4902 y paso por San Juan del Cesar.

El valor del contrato ascendía a \$ 693578 068. Se declaró su caducidad por Resolución 0030 del 7 de enero de 2009. Al contratista se le entregó la suma de $\$ 366012009$ como anticipo. Con dichos recursos se ejecutaron y fueron recibidas obras por valor de \$ 162542 149. Así mismo, reintegró la suma de \$ 39949000. De acuerdo con lo anterior y con lo certificado por el Invías, el contratista no amortizó ni devolvió la suma de \$ 163520860.

En el auto que decide el grado de consulta se resalta la negligencia del contratista de obra, que dio lugar al daño al patrimonio público, en la cuantía referida.

El cuarto caso que se estudiará corresponde al resuelto mediante Auto 000388 de 1 abril de 2019, que decide el grado de consulta en contra del fallo No. 020 proferido en el Proceso 2016-00520, donde resolvió fallar con responsabilidad fiscal, a título de culpa grave, en cuantía de \$ 88361 919, de forma solidaria en contra de los representantes legales de las entidades contratantes (alcaldes de los municipios del Valle de San Juan), de los funcionarios que tuvieron a su cargo la vigilancia y el seguimiento a la ejecución del contrato, del interventor externo del contrato y de la Fundación para el Desarrollo Integral Sostenible Medio Ambiental 
(Fudismedio) (Cooperante-Convenio No 154 de 2007). En esta ocasión también se declararon como terceros civilmente responsables a las compañías aseguradoras y se incorporaron al fallo, con responsabilidad fiscal, las pólizas respectivas.

En ese auto se confirmó la decisión de fallar con responsabilidad fiscal, porque se demostró que los recursos de regalías entregados como anticipo al cooperante para la ejecución del Convenio 154 de 2007 no cumplieron con su objeto, pues se destinaron a 31 de las 50 viviendas que debían ejecutarse y las obras realizadas presentaban múltiples falencias que tuvieron su origen en la falta de planeación y en la omisión de cumplir con el deber de vigilancia y seguimiento a la ejecución de los contratos, lo que dio lugar a un detrimento patrimonial de \$ 69046314 .

La quinta decisión que se tendrá como insumo corresponde al Auto 00566 del 30 de noviembre de 2018, por el cual se resolvió el recurso de apelación y se decidió el grado de consulta en relación con el fallo con responsabilidad fiscal 013 del 23 de agosto de 2018, proferido en el Proceso 06-016-2013, en el que se declaró la existencia de responsabilidad por la omisión de amortizar totalmente el anticipo entregado en virtud del Contrato 1663 del 14 de septiembre de 2005, celebrado por el Invías, cuyo objeto fue el diseño, la reconstrucción, la pavimentación o repavimentación de la vía grupo 43, en el tramo 1 Cambao-Puerto Bogotá, del k0+000 al k40+000, con una longitud de 40 kilómetros en el departamento de Cundinamarca, en cuantía de \$139609514.

En esta decisión se resaltó la omisión de amortizar el anticipo como causa del daño y se evidenció que no había prueba de acciones efectivas por parte del Invías encaminadas a la recuperación de estos recursos.

Con base en los casos planteados se establece que, mediante fallos fiscales y autos que deciden el grado de consulta, la Contraloría cumple con su función en cuanto al conocimiento y al trámite de procesos de responsabilidad fiscal, en este caso, por el mal manejo del anticipo por parte de contratistas, gestión por la cual se consideran gestores fiscales, ${ }^{45}$ algunas veces con alcance a las interventorías respectivas, y determina como causa de dicha responsabilidad la ineficiencia en la vigilancia y el seguimiento a la ejecución de los anticipos, como inconsistencias en la planeación, selección, ejecución y seguimiento de las obras.

45 República de Colombia, Contraloría General de la Nación, "Auto 00566 del 30 de noviembre de 2018. Proferido en el expediente 06-016-2013/PRF 2014 -0563”. 
Si bien existen casos en los que se vincula a la interventoría y a la supervisión, el análisis pone de presente que esta situación concurre en un pequeño porcentaje, lo que, de una parte, muestra la relevancia de la correcta y oportuna vigilancia en el seguimiento de la ejecución de los recursos del anticipo y, de otra, que este mecanismo no resulta efectivo, dado que el riesgo de daño por la indebida amortización del anticipo se puede concretar, a pesar de que la entidad contratante, con la supervisión o de la interventoría, cumple con el referido deber.

En cuanto al alcance territorial debe manifestarse que las decisiones analizadas dan cuenta de que los problemas por la indebida inversión del anticipo o la omisión de su amortización completa se presentan respecto a contratos celebrados por entidades de orden a nacional y territorial. Así mismo, indican que la situación se puede presentar en entidades centrales o descentralizadas de la Administración pública, lo que demuestra que se trata de un asunto transversal a la contratación estatal.

Ahora bien, como se puede apreciar, solo uno de los contratos mencionados no es de obra, por lo que se trata de un problema asociado a esta tipología. Es más, en dicho caso, si bien se celebró un convenio de asociación con una fundación, el objeto del contrato era la construcción de viviendas.

Resulta de especial relevancia que, en relación con los contratos celebrados en vigencia de la Ley 1474 de 2011, según cifras oficiales de la Contraloría General de la República del año 2021, en 396597 contratos celebrados entre abril de 2019 y febrero de 2020, se pactaron anticipos por 19679 millones de pesos; sin embargo, en el 22 \% de ellos, el gasto no se ajustó a la finalidad del acuerdo. Los departamentos de Nariño, Casanare, Santander, Valle de Cauca y Córdoba encabezan la lista.

Como datos adicionales de la Contraloría Delegada para la Responsabilidad Fiscal, se tiene que entre los años 2015 y 2020, la Contraloría General de la República ha emitido 1037 fallos con responsabilidad fiscal por valor de \$ 825324 000; 1544 casos de resarcimiento en procesos de responsabilidad fiscal e indagaciones preliminares, por valor de $\$ 5,49$ billones; recaudos por cobro coactivo por valor de $\$ 440331$ millones; y resarcimiento en la intervención de procesos penales por valor de \$ 30093 millones.

Por último, cabe resaltar la labor que viene realizando la Contraloría General de la República en la búsqueda del fortalecimiento de los mecanismos de protección de los recursos públicos, con la modernización de la entidad y la expedición del Acto 
legislativo 04 de 2019, "Por medio del cual se reforma el régimen de control fiscal", reglamentado por el Decreto 403 de 2020, que apunta a fortalecer el control fiscal en Colombia.

Este fortalecimiento tiene por objeto lograr que el control fiscal ejercido por las entidades, llámense Contraloría General de la República o contralorías distritales, departamentales o regionales, vigilen estos recursos en todos los momentos del proceso contractual. Es así como se pretende que el control fiscal, "además de ser posterior y selectivo, podrá ejercerse de manera preventiva y concomitante, según sea necesario para garantizar la defensa y protección del patrimonio público". ${ }^{46}$ Se otorga a la Contraloría General de la República la competencia prevalente para ejercer control sobre la gestión de cualquier entidad territorial o para realizar acciones conjuntas entre contralorías cuando el sujeto, el objeto o la actividad de control lo amerite.

\section{Conclusiones}

El anticipo contractual es una figura contemplada en la legislación colombiana que permite al contratista recibir de la entidad contratante un adelanto en dinero para costear los gastos derivados de la iniciación de la ejecución del contrato. Como no constituye un pago, estos recursos forman parte del patrimonio del Estado y no se integran al patrimonio del contratista. Así las cosas, este monto deberá amortizarse en cada uno de los pagos que se realicen en el respectivo contrato, conforme las reglas que se hayan fijado para el efecto.

En el ordenamiento jurídico colombiano existe una serie de mecanismos que le permiten a la entidad contratante mitigar el riesgo de detrimento patrimonial. Sin embargo, dichas herramientas no son eficaces a la hora de cumplir su cometido, toda vez que la mayoría de ellas no se encuentra diseñada para ser utilizada en las etapas iniciales del contrato, lo cual no facilita hacer un control oportuno, puesto que se usan cuando el daño patrimonial al erario ya se ha consumado por parte del contratista.

Estos mecanismos permiten al Estado establecer, por lo menos, cuatro tipos de responsabilidades: i) contractual; ii) penal; iii) fiscal, y iv) disciplinaria.

46 República de Colombia, Presidencia de la República, Acto Legislativo 4 de 2019, "Por medio del cual se reforma el Régimen de control fiscal" (Bogotá: Diario Oficial núm. 51 080, 18 de septiembre 2019), art. 1. 
Aunque la fiducia mercantil, consagrada para cierto tipo de contratos en la legislación vigente, disminuye los riesgos asociados a la ejecución de los recursos entregados a título de anticipo, no ofrece garantía suficiente para los recursos que ingresa a la fiduciaria, en tanto la libertad de configuración del contrato de fiducia es amplia y se permite que la fiduciaria y el contratista definan las reglas conforme a las cuales se realizará el giro de los recursos por parte de la entidad pública y su posterior desembolso y el pago a terceros.

El indebido manejo de los recursos del anticipo lleva implícito el incumplimiento de los cronogramas de ejecución y, en muchos casos, la no culminación exitosa del contrato o, en su defecto, el incremento excesivo del costo planificado, producto de las adiciones presupuestales que debe hacer la entidad para poder llevar a cabo el objeto contratado.

Analizados algunos fallos emitidos por la Contraloría General de la República, se puede entender con mayor claridad la aplicación de los procedimientos para dar cumplimiento a las obligaciones impuestas por el artículo 267 de la Constitución Política, modificado por el Acto legislativo 04 de 2019.

Con la entrada en vigor del Decreto 403 de 2020, mediante el cual se reglamentó el Acto legislativo 04 de 2019, "Por medio del cual se reforma el régimen de control fiscal", el Estado colombiano busca fortalecer el control fiscal que ejercen los entes encargados, como la Contraloría General de la República y las contralorías distritales, departamentales y regionales, con el fin de que no solo sea ejercido de forma posterior como, inicialmente fue concebido, sino también previo y concomitante, es decir, antes, durante y después de las etapas del contrato.

\section{Referencias}

Alarcón Quiroga, Harol Alexander. "Contratación estatal comparada con Argentina". Novum Jus 4, núm. 1 (2010): 205-236. https://novumjus.ucatolica.edu.co/article/ view/707/723 (acceso febrero 28, 2022).

Benavides, Juan. "Public Contracts and Institutional Weakness in Infrastructure in Colombia”. Revista de Ingeniería, núm. 32 (2010): 80-87, http://www.scielo.org.co/ scielo.php?script=sci_abstract\&pid=S0121-49932010000200012\&lng=en\&nrm=is $\&$ tlng=en (acceso agosto 25, 2021).

Borrero Restrepo, Ligia Helena. "El control fiscal a la gestión fiscal de los particulares que manejan fondos y bienes públicos, 2011”. https://www.contraloria.gov.co/ 
documents/20181/257118/Control+Fiscal+a+Particulares.pdf/b3f22d60-8bef-439b9caf-bacbf694e699?version=1.0 (acceso agosto 25, 2021).

Colombia Compra Eficiente. "Concepto 3185 del 21 de febrero de 2018". https:// crconsultorescolombia.com/concepto-no-3105-anticipo-pago-anticipado.php (acceso septiembre 25, 2021).

Cubides Cárdenas, Jaime, Julián Enrique Pinilla Malagán, Jheison Torres Ávila y Germán Vallejo Almeida. "Derecho público en el siglo XXI: regulación del mercado, contratación pública y derechos humanos", colección JUS Derecho Público, núm. 15. Bogotá: Universidad Católica de Colombia, 2016.

Dávila Vinueza, Luis Guillermo. Régimen jurídico de la contratación estatal: aproximación crítica a la Ley 80 de 1993. Bogotá: Legis, 2003.

De la Torre Vargas, David. "Régimen Jurídico de los contratos celebrados por el gestor en los planes departamentales de agua". Revista Digital de Derecho Administrativo, núm. 5 (2011): 129-151, https://revistas.uexternado.edu.co/index.php/Deradm/article/ view/2956 (acceso agosto 25, 2021).

Díaz, Enrique. "Publicidad y oponibilidad de la fiducia mercantil en garantía" en Estudios de derecho privado, coordinado por Alejandro Venegas, Juan Pablo Cárdenas y Fabricio Mantilla, 329-335. Tomo I. Bogotá: Universidad del Rosario, 2009.

Galofre Amín, Paula Andrea. "El esquema fiduciario en la contratación estatal, su aplicación en el contrato de concesión infraestructura vial: el manejo de los recursos de la concesión a través del negocio fiduciario". Tesis de maestría, Universidad Externado de Colombia, 2006.

González Duarte, Cristina. "El anticipo en el contrato estatal: concepto, derechos, obligaciones y responsabilidades asociadas". Tesis de pregrado, Universidad Eafit, 2011.

Laverde Álvarez, Juan Manuel. Manual de procedimiento administrativo sancionatorio. 2a ed. Bogotá: Legis, 2018.

Matallana Camacho, Ernesto. Manual de contratación de la Administración pública: reforma de la Ley 80 de 1993. Bogotá: Universidad Externado de Colombia, 2009.

Mateus Londoño, Diana Lorena. "Debido proceso probatorio en el procedimiento sancionatorio contractual en Colombia". Revista digital de derecho administrativo, núm. 24, (2020): 183-211.

Pérez Rueda, Carlos Eduardo. "El amparo de anticipo en el seguro de cumplimiento entre particulares". RIS 37, núm. 21 (2012): 191-212, https://revistas.javeriana.edu.co/ index.php/iberoseguros/article/view/11469/10001 (acceso agosto 25, 2021).

República de Colombia, Congreso de la República. Ley 1150 de 2007, "Por medio de la cual se introducen medidas para la eficiencia y la transparencia en la Ley 80 de 1993 y se dictan otras disposiciones generales sobre la contratación con recursos públicos". Bogotá: Diario Oficial núm. 46 691, 16 de julio de 2007. 
República de Colombia, Congreso de la República. Ley 1474 de 2011, "Por la cual se dictan normas orientadas a fortalecer los mecanismos de prevención, investigación y sanción de actos de corrupción y la efectividad del control de la gestión pública". Bogotá: Diario Oficial núm. 48 128, 12 de julio de 2011.

República de Colombia, Congreso de la República. Ley 734 de 2002, "Por la cual se expide el Código Disciplinario Único". Bogotá: Diario Oficial núm. 44 708, 13 de febrero de 2002.

República de Colombia, Congreso de la República. Ley 80 de 1993, "Por la cual se expide el Estatuto General de Contratación de la Administración Pública”. Bogotá: Diario Oficial núm. 41 094, 28 de octubre de 1993.

República de Colombia, Consejo de Estado, Sala de lo Contencioso Administrativo, Sección Tercera. Sentencia del 31 de enero de 1991. Radicado 4739. M. P. Julio César Uribe Acosta. República de Colombia, Consejo de Estado, Sala de lo Contencioso Administrativo, Sección Tercera. Sentencia del 13 de septiembre de 1999. Radicado 10 607. M. P. Ricardo Hoyos Duque.

República de Colombia, Consejo de Estado, Sala de lo Contencioso Administrativo, Sección Primera. Sentencia del 23 de agosto de 2019. Expediente 2001-23-31-000-2012-00047 011. C. P. Hernando Sánchez Sánchez.

República de Colombia, Consejo de Estado, Sala de lo Contencioso Administrativo, Sección

Tercera, Subsección C. Sentencia del 9 de julio de 2018. Expediente 42 171. C. P. Jaime Enrique Rodríguez Navas.

República de Colombia, Consejo de Estado. Sala de lo Contencioso Administrativo. Sentencia

del 8 de agosto de 2001. Expedientes acumulados AC10966 y AC11275. M. P. María Elena Giraldo Gómez.

República de Colombia, Contraloría General de la Nación. "Auto 00566 del 30 de noviembre de 2018. Proferido en el expediente 06-016-2013/PRF 2014 -0563”.

República de Colombia, Contraloría General de la República. "Auto ORD-80112-0250-2018. Noviembre 02 de 2018 en el PRF 80853-266-03677".

República de Colombia, Contraloría General de la República. "Auto 0015 del 19 de enero de 2019. PRF. 2013 IE 012015316-031-13/6-031-13”.

República de Colombia, Contraloría General de la República. "Concepto Jurídico No. 7461. Febrero 07 de 2006”. https://www.yumpu.com/es/document/read/51399181/ el-anticipo-en-contratos-estatales-el-anticipo-es-la-suma- (acceso agosto 25, 2021). República de Colombia, Corte Constitucional. Sentencia C-563 de 7 de octubre de 1998. M. P. Antonio Barrera Carbonell y Carlos Gaviria Díaz.

República de Colombia, Corte Constitucional. Sentencia T-569 de 8 de octubre de 1998. M. P. Alfredo Beltrán Sierra. 
República de Colombia, Corte Suprema de Justicia, Sala de Casación Civil. Sentencia del 3 de agosto de 2005. Expediente 1909. M. P. Silvio Fernando Trejos Bueno.

República de Colombia, Presidencia de la República. Acto Legislativo 4 de 2019, "Por medio del cual se reforma el Régimen de control fiscal”. Bogotá: Diario Oficial núm. 51 080, 18 de septiembre 2019.

República de Colombia, Presidencia de la República. Decreto 1082 de 2015, "Por medio del cual se expide el Decreto único reglamentario del sector administrativo de planeación nacional”. Bogotá: Diario Oficial núm. 49 523, 26 de mayo de 2015.

República de Colombia, Presidencia de la República. Decreto 410 de 1971, "Por el cual se expide el Código de Comercio". Bogotá: Diario Oficial núm. 33 339, 16 de junio de 1971.

República de Colombia, Senado de la República. Proyecto de Ley 142 de 2010, "Proyecto de ley por el cual se dictan normas orientadas a fortalecer los mecanismos de prevención, investigación y sanción de actos de corrupción y la efectividad del control de la gestión pública”. Bogotá: Gaceta del Congreso núm. 607, 6 de septiembre de 2010.

República de Colombia. Contraloría General de la República. "Concepto Jurídico 2015EE0054117". Mayo 4 de 2015. https://vlex.com.co/vid/concepto-n-cgr-oj-797797673 (acceso agosto 25, 2021).

Santofimio Gamboa, Jaime Orlando. Tratado de derecho administrativo. Tomo IV: Contratación indebida. Bogotá: Universidad Externado de Colombia, 2004.

Sierra Ospina, Santiago. "El anticipo en el contrato estatal: generalidades y mecanismos de protección”. Tesis de pregrado, Universidad Pontificia Bolivariana, 2011.

Superintendencia Financiera de Colombia. "Circular Básica Jurídica (Circular Externa 007 de 1996)”. https://vlex.com.co/vid/circular-externa-basica-juridica-398669581 (acceso agosto 25, 2021).

Vásquez Gómez, Jean Paul y Lilia Yaneth Álvarez Quiroz. El debido proceso en actuaciones administrativas contractuales sancionatorias. Medellín: Lijursánchez, 2018. 